\title{
The beliefs, and reported and intended behaviors of unaffected men in response to their family history of prostate cancer
}

Ruth Cowan, BSc ${ }^{1,2}$, Bettina Meiser, PhD ${ }^{3,4}$, Graham G. Giles, PhD ${ }^{5}$, Geoffrey J. Lindeman, PhD, FRACP ${ }^{2}$, and Clara L. Gaff, PhD ${ }^{2,6}$

\begin{abstract}
Purpose: Genetic testing for hereditary cancer facilitates medical management and improves health outcomes. Genetic testing is not currently available for prostate cancer, but trials are underway to investigate if antiandrogens and selenium have a preventive role for at-risk individuals. To inform future genetic counseling, we sought to understand the pre-existing beliefs and behaviors of men with a family history of prostate cancer and explore their intention to adopt possible preventive behaviors in response to test results. Methods: A survey was completed by 280 men (response: 59\%). Results: The belief that diet influenced prostate cancer risk was held by $73 \%$ of participants, whereas $37 \%$ believed in medication/natural therapies. Thirty-nine percent reported at least one change to their diet, alcohol consumption, smoking, exercise patterns, vitamin/mineral/supplement intake and/or medication/natural therapy in response to their family history. The men expressed interest in genetic testing with 92\% "definitely" or "probably" interested. Definite interest was associated with number of affected relatives and prostate cancer-related anxiety. A positive genetic test would motivate $93 \%$ of men to make at least one behavioral change. Conclusions: Participants commonly believed behavioral factors influenced prostate cancer risk and reported that they would alter their behavior to reduce risk after (hypothetical) genetic testing. Genet Med 2008: 10(6):430-438.
\end{abstract}

Key Words: genetic services, health behavior, prevention, genetic testing, hereditary cancer syndrome, men, prostate cancer

In general, men are less proactive about maintaining health than women: they are more likely to engage in risk-taking behaviors (e.g., eating poorly, failing to exercise), ${ }^{1}$ and less likely to attend health services ${ }^{2}$ and to engage in preventive and screening programs. ${ }^{2}$ Although it was initially believed that men may have a lower uptake of genetic testing, ${ }^{3}$ more recently it has been suggested that these differences do not exist when effective treatment is available. ${ }^{4}$ In socialized medical systems, where it is implicit that funded provision of services will ultimately lead to improved public health outcomes, ${ }^{5}$ these conflicting data provide both an opportunity and a challenge for

\footnotetext{
From the ${ }^{1}$ Department of Paediatrics, The University of Melbourne, Parkville, Victoria, Australia; ${ }^{2}$ Familial Cancer Centre, The Royal Melbourne Hospital, Parkville, Victoria, Australia; ${ }^{3}$ Psychosocial Research Group, Department Medical Oncology, Prince of Wales Hospital, Randwick, New South Wales, Australia; ${ }^{4}$ Prince of Wales Clinical School, The University of New South Wales, New South Wales, Australia; ${ }^{5}$ Cancer Epidemiology Centre, The Cancer Council of Victoria, Carlton, Victoria, Australia; and ${ }^{6}$ Genetic Health Services Victoria, Parkville, Victoria, Australia.

Clara L. Gaff, PhD, Genetic Health Services Victoria, PO Box 1100, Parkville VIC 3052, Australia.E-mail: clara.gaff@ghsv.org.au.

Disclosure: The authors declare no conflicts of interest.

Submitted for publication November 28, 2007.

Accepted for publication February 27, 2008.

DOI: $10.1097 /$ GIM.0b013e31817701c1
}

genetic services providing predictive genetic testing for treatable and potentially preventable genetic conditions. Understandably, research on relatively well-defined hereditary cancer conditions, caused by known susceptibility genes, has focused on uptake of genetic testing and the impact of genetic testing on psychological well being and participation in surveillance. ${ }^{6}$

Lifestyle modification for those with a risk of cancer on the basis of their family history has been less well explored. Generally, the effect of "lifestyle" factors such as diet and exercise on hereditary predisposition to known cancer syndromes is not clear, whereas the benefits of surveillance and preventive surgery are relatively better known. ${ }^{7,8}$ Prostate cancer stands in contrast to cancers with a well-described hereditary basis, such as colorectal cancer and breast cancer. Although a family history of prostate cancer confers an increased risk of developing this condition and it has been proposed that up to a third of cases diagnosed before 60 years are potentially caused by dominantly inherited mutations in susceptibility genes, ${ }^{9}$ the identification of susceptibility genes with mutations conferring a high risk of prostate cancer (in the absence of a family history of breast/ovarian cancer) has eluded researchers. Genetic testing for a predisposition to prostate cancer is, therefore, currently not possible. Further, surveillance by serum prostate- 
specific antigen testing is controversial, as it contributes to the over diagnosis of tumors of low metastatic potential and its influence on prostate cancer mortality is not known. ${ }^{10}$ However, prevention through diet supplementation and medication does show some promise. For example, selenium supplementation in a randomized trial of skin cancer prevention resulted in fewer prostate cancer cases than expected, ${ }^{11}$ and large scale trials are currently underway to determine its effectiveness as a preventive agent in the general population. ${ }^{12}$ The antiandrogen finasteride has been shown to reduce the risk of prostate cancer; however a possible higher risk of aggressive prostate cancer has made use of this agent as a preventative contentious. ${ }^{13,14}$ Moyad and Caroll ${ }^{15,16}$ propose lifestyle recommendations to prevent prostate cancer, predominantly suggesting dietary changes, physical activity, smoking cessation, and moderating alcohol consumption, arguing that although evidence for the roles of these behaviors in prostate cancer risk reduction is currently weak, there are other health benefits to this regimen and no harm. Although the potential of these medical and lifestyle modifications to influence the prostate cancer risk of those with a family history is not yet known, this is an area of current research.

It has been proposed that genetic counseling for adult-onset chronic health conditions should promote health behaviors that may be protective. ${ }^{17}$ Although evidence-based advice on health behavior is necessary, it is also helpful to understand the pre-existing beliefs and health behaviors of those likely to attend familial cancer services as these can influence emotional response and behavioral response to health information. ${ }^{18}$ The relevance of personal beliefs (illness representations) about a genetic condition to genetic testing and health behaviors has been described by Shiloh. ${ }^{18}$ Beliefs about disease causation have been shown to influence behavioral responses to negative predictive genetic tests for Familial Adenomatous Polyposis ${ }^{19,20}$ and perceived preventability is important for interest in predictive genetic testing. ${ }^{21}$ As a starting point to ascertain the beliefs and behaviors of men with a family history of prostate cancer in relation to genetic testing, we conducted a cross-sectional survey. No information about prostate cancer or genetic testing was provided by the researchers, in order that men would respond on the basis of their existing beliefs and assumptions. Specifically, we sought to ascertain (1) beliefs about the role of putative prostate cancer risk reducing agents; (2) the anticipated impact of genetic testing on possible risk reducing behaviors; and (3) the psychological determinants of interest in genetic testing, in particular the potential role of depression, generalized anxiety, prostate cancer anxiety, and/or individual information-seeking style. ${ }^{22}$

\section{MATERIALS AND METHODS}

\section{Sample}

Respondents were recruited from two existing resources. The first was a register of 179 men held at the Urology Department at the Royal Melbourne Hospital. These men were orig- inally ascertained through advertisements in the print media, inviting men who self-reported a family history of prostate cancer to register with a view to participating in research on familial prostate cancer. The family histories of these men have not been verified. No previous research had been performed on these men at the time of this survey. This cohort is referred to as the "self-selected sample" in the text.

The second source of ascertainment was The Australian Prostate Cancer Family Study held by The Cancer Council of Victoria. Eligible men were identified by affected relatives who were recruited as cases to a population-based casecontrol study. Eligibility and recruitment procedures have been previously described. ${ }^{23}$ For the current study, a subgroup of these respondents was selected on the basis of family history, comprising two or more relatives with prostate cancer or one relative with prostate cancer diagnosed before 55 years of age. In the text, this sample is referred to as the "family study sample."

Additional eligibility criteria for both samples were no prior diagnosis of prostate cancer, an ability to give informed consent and literacy in English, because data were collected using self-reported questionnaires.

\section{Procedure}

This study was undertaken as part of a larger study that also assessed the accuracy and completeness of reporting family history of prostate cancer, ${ }^{24}$ information and clinical service needs, ${ }^{25}$ and surveillance practices. ${ }^{26}$ The study was approved by the ethics committees of Melbourne Health and The Cancer Council Victoria. Questionnaires and reply paid envelopes were mailed through each of the primary study centers. The package included an approach letter outlining the purpose of the study, a questionnaire and a reply paid envelope. A reminder letter was sent to respondents 1 month after the initial mail out by the participating centers. Return of a completed questionnaire was accepted as consent for participation.

\section{Measures}

The questionnaire included both previously validated and new, purposively designed items assessing beliefs about risk factors and behavior changes, which were generated based on clinical observation and a review of the relevant literature. The questionnaires were pilot-tested with 25 men, which did not lead to changes in the wording of the newly designed items described here. Hence the 25 questionnaires administered as part of the pilot phase were included in the final sample.

\section{Sociodemographic variables}

These included age; marital status; level of education; number; age of diagnosis and relationship of relatives with prostate cancer; and whether the respondent had sons.

\section{Risk perception}

A visual analogue scale anchored by $0-100 \%$ assessed perceived lifetime risk by age 75 . A visual analogue scale, rather than a Likert-type scale or a scale in which intermediate posi- 
tions are labeled with adjectives, was chosen because of its simplicity and widespread use in medicine to assess a variety of constructs $^{27}$ and to allow comparisons with related studies which used visual analogue scales to assess perceived risk. ${ }^{28,29}$

\section{Beliefs about potential risk-modifying factors}

Respondents indicated, by ticking yes/no boxes, if they believed that any of the following "may affect a man's risk of developing prostate cancer": diet, how much alcohol a man drinks, smoking practices, exercise, medication and/or natural therapies, vitamin and mineral supplements. Additional response options were "other" or "chance cannot be altered."

\section{Potentially risk-modifying behavior changes}

Respondents indicated, by ticking yes/no boxes, if they "had made changes to your lifestyle because of your family history of prostate cancer" in the following: diet, how much alcohol you drink, smoking practices, exercise practices, medication and/or natural therapies, vitamin and mineral supplements, how often you have check-ups and the type of check-ups. Additional response options were "other" and "I have made no changes." These items were included in a different section of the questionnaire to avoid repetitive completion of similarly phrased items. Men who responded that they did not smoke or drink alcohol were excluded from the calculation of percentages relating to smoking or alcohol behavior and intention.

\section{Interest in genetic testing}

Respondents were asked if they would want a genetic test "if it could tell you that you are more likely than average to develop prostate cancer." No detail was given about the nature of genetic testing or about the information that testing may provide. Response options were definitely not; probably not; yes, probably; yes, definitely; do not know. Respondents were also asked why they thought "genetic testing for prostate cancer would/would not be helpful" in an open-ended response question. Answers were grouped thematically, with two researchers (R.C. and C.G.) reaching agreement on the coding of responses.

\section{Anticipated behavior response to genetic testing}

Respondents indicated, by ticking yes/no boxes, if they would make any of the following changes if a genetic test showed "you were more likely than average to develop prostate cancer: your diet, how much alcohol you drink, your smoking practices, your exercise, medication and/or natural therapies, vitamin and mineral supplements, how often you have checkups and the type of check-ups." Additional response options were "other" and "I would change nothing."

\section{The Impact of Events Scale}

This 15 -item scale was used to measure prostate cancer anxiety. The Impact of Events Scale (IES) is a validated measure of intrusion and avoidance in relation to a specific stressor. ${ }^{30}$ In this study, the particular stressor was concern about being at risk of prostate cancer. The IES has been used previously in related studies. ${ }^{31,32}$ The intrusion and avoidance subscales were found to have excellent internal consistency in the current sample with a coefficient $\alpha$ of 0.87 each.

\section{Hospital Anxiety and Depression Scale}

This is a widely used measure of emotional disturbance and has two subscales measuring anxiety and depression. ${ }^{33}$ The Hospital Anxiety and Depression Scale (HADS) has been validated for use in a cancer setting ${ }^{34}$ and has been used previously in related studies. ${ }^{31}$ In this study, only the seven-item depression subscale was used as previous studies suggest individuals with depression are less likely to pursue genetic testing. The Depression Scale of the HADS has been shown to possess high internal consistency and separate use of the scale is justified..$^{35}$ The Depression Subscale demonstrated excellent internal consistency in the current sample with a coefficient $\alpha$ of 0.79 .

\section{Monitoring-Blunting Scale}

The Miller-Behavioral Style Scale is a four-item, validated scale, which measures individual information-seeking style, that is individual differences in coping styles in threatening situations. ${ }^{22}$ Respondents were asked to imagine four stressprovoking scenarios of a largely uncontrollable nature. Each scenario was followed by eight statements representing different attention strategies for dealing with the event, i.e., "monitoring" (attending to) versus "blunting" (avoiding) potentially threatening information. Scores for monitoring and blunting are calculated separately by adding the number of items ticked, and the monitoring minus blunting score was used for analysis. ${ }^{22}$

\section{Statistical analyses}

The Statistical Package for the Social Sciences, Version 11.0, was used for all analyses. Descriptive statistics were used to describe the sample in terms of sociodemographic and family history data, interest in genetic testing and lifestyle beliefs, practices and anticipated changes. The variable "interest in genetic testing" was recoded as a binary variable for further analysis. As only $5 \%$ of respondents were "definitely not" or "probably not" interested and actual uptake of genetic testing for cancer predisposition has been observed to be lower than intended uptake, ${ }^{36}$ these responses were collapsed with "yes, probably." To assess univariate associations between categorical predictor variables (educational level, type of sample, having sons or not, and marital status) and the outcome variable (interest in genetic testing), $\chi^{2}$ tests were performed. MannWhitney $U$ tests were conducted for non-normal interval variables (age, number of first- and second-degree relatives affected, perceived prostate cancer risk and prostate cancer anxiety). Finally, a two-sample $t$ test was used for normally distributed data, i.e., monitoring minus blunting scores. All independent variables with a bivariate association of $P<0.1$ with the outcome variable were entered into a binary logistic regression equation. To explore whether the relationship between each of the potential predictor variables and the outcome variables varied by recruitment source, appropriate interaction terms were tested for significance. 
Table 1

Sociodemographics and family history variables of study sample $(N=280)^{25}$

\begin{tabular}{|c|c|c|c|c|c|c|c|}
\hline \multirow[b]{2}{*}{ Variable } & \multirow[b]{2}{*}{ Level } & \multicolumn{2}{|c|}{ Family study sample } & \multicolumn{2}{|c|}{ Self-selected sample } & \multicolumn{2}{|c|}{ Total sample } \\
\hline & & $N$ & $\%$ & $N$ & $\%$ & $N$ & $\%$ \\
\hline \multirow[t]{3}{*}{ Age } & $<55$ & 68 & 44.4 & 54 & 43.2 & 122 & 43.9 \\
\hline & $55-65$ & 35 & 22.9 & 55 & 44.0 & 90 & 32.4 \\
\hline & $66+$ & 50 & 32.7 & 16 & 12.8 & 66 & 23.7 \\
\hline \multirow[t]{2}{*}{ Marital status } & Partner & 131 & 84.5 & 103 & 82.4 & 234 & 83.6 \\
\hline & No partner & 24 & 15.5 & 22 & 17.6 & 46 & 16.4 \\
\hline \multirow[t]{2}{*}{ Biological sons } & Yes & 118 & 76.1 & 83 & 66.9 & 201 & 72.0 \\
\hline & No & 37 & 23.9 & 41 & 33.1 & 78 & 28.0 \\
\hline Educational level & No postschool & 93 & 61.6 & 54 & 43.9 & 147 & 53.6 \\
\hline Postschool & & 58 & 38.4 & 69 & 56.1 & 127 & 46.4 \\
\hline \multirow{4}{*}{$\begin{array}{l}\text { Number of first-and second-degree } \\
\text { relatives with prostate cancer }\end{array}$} & $0^{a}$ & 13 & 8.4 & 2 & 1.6 & 15 & 5.4 \\
\hline & 1 & 81 & 52.3 & 100 & 80.0 & 181 & 64.6 \\
\hline & $2-3$ & 46 & 29.7 & 21 & 16.8 & 67 & 24.0 \\
\hline & $4-6$ & 15 & 9.6 & 2 & 1.6 & 17 & 6.1 \\
\hline
\end{tabular}

${ }^{a}$ Participants had third-degree or higher relatives diagnosed with prostate cancer.

\section{RESULTS}

\section{Response and respondent characteristics}

As reported previously, ${ }^{25,26}$ a total of 504 questionnaires were mailed out; 23 packages were returned to sender, and eight men were found to be deceased. Of the remaining 473 eligible participants, 59\% (51\% in the family study and $73 \%$ in the self-selected sample) returned completed questionnaires. The majority of respondents was in a relationship (83\%) and had biological sons $(72.0 \%)$. Table 1 provides a summary of the sociodemographic and family history characteristics of the sample.

With respect to psychological characteristics of the sample, the mean total score for cancer-specific worry using the IES was 7.25 (SD 10.61, range 0-75), with mean scores on the Intrusion and Avoidance subscale of 3.07 (SD 4.95, range 0-35) and 4.49 (SD 7.01, range $0-40$ ), respectively. The mean HADS depression score was 2.90 (SD 2.7, range $0-21$ ). The mean monitoring minus blunting score was 5.53 (SD 3.82, range -32 to 32).

\section{Beliefs about, and behaviors relating to, potential risk-modifying factors}

The majority of respondents believed that prostate cancer risk could be modified: a mean of 2.6 (range 1-6) items were endorsed by respondents as potential risk-modifying factors. Figure 1 shows the percentages of men indicating a belief in a range of potential risk-modifying behaviors, and the actual change made to these behaviors or intended change in the event that a genetic testing result indicates an increased risk. The most commonly held belief was that diet could influence prostate cancer risk, with $73 \%$ of participants identifying it as affecting a man's chance of developing prostate cancer. Belief was lowest for vitamins and minerals (36\%) and medication/ natural therapies (37\%). Thirty-nine percent of men reported having already made at least one potentially risk modifying behavior change, other than changes in surveillance, in response to their family history of prostate cancer. In all cases, the frequency of reported behavior changes for each item was

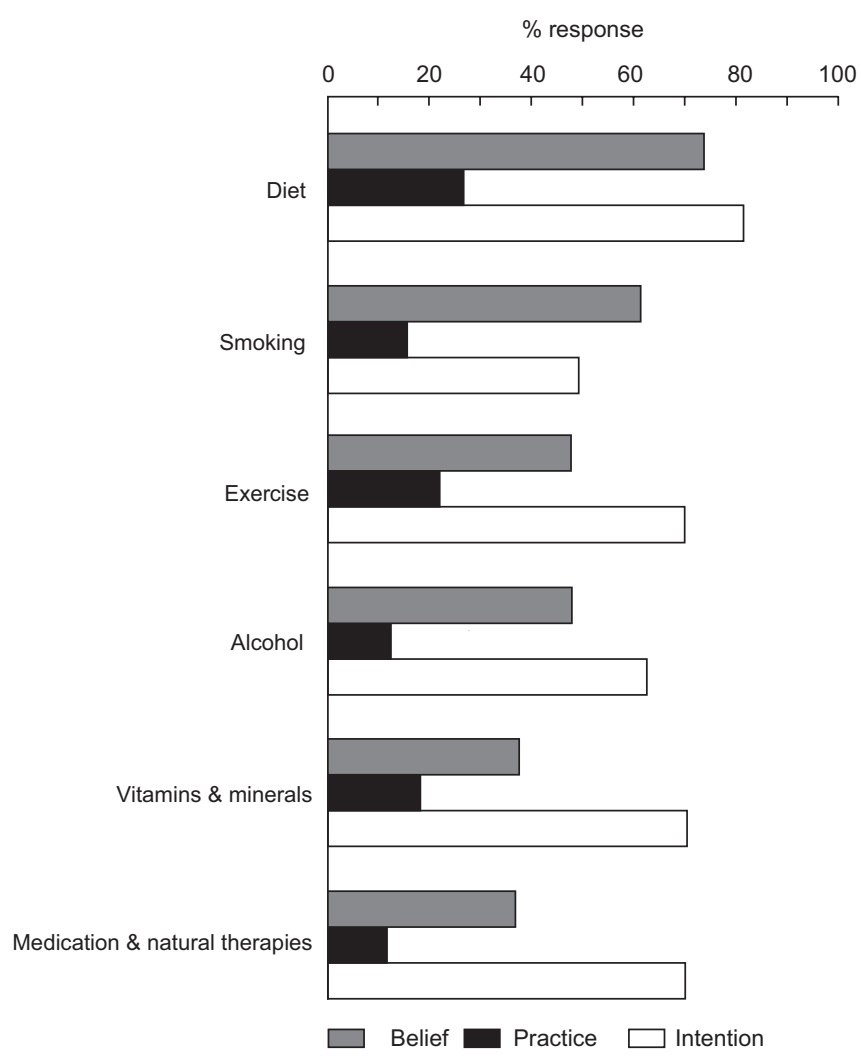

Fig. 1. Health behavior beliefs, reported practice and anticipated change in response to genetic testing. 
smaller in magnitude than the frequency of belief in the potentially risk-modifying role of that item (Fig. 1). Sixty-two percent of men reported having made no behavior changes, and $1 \%$ having made all the changes. Almost half had changed frequency (49\%) and type of check-ups (46\%) in response to their family history of prostate cancer. Having made at least one behavior change, other than screening, was not associated with type of sample, sociodemographic or family history variables and/or perceived prostate cancer risk and/or anxiety (data not shown).

\section{Interest in genetic testing}

Interest in genetic testing was assessed without providing any information about its implications or possible outcomes, as we wished to determine pre-existing beliefs and attitudes that men may hold before attending a clinical service rather than determine the impact of a specific intervention. The majority of men reported some interest in genetic testing with $68 \%$ "definitely" and 26\% "probably" interested, whereas 5\% indicated being "probably" or "definitely not" interested in genetic testing and only $1 \%$ were unsure. The results of bivariate analyses are shown in Table 2. Several variables were significantly associated with definite interest in genetic testing for prostate cancer, namely recruitment in the self-selected sample $\left(\chi^{2}=8.98 ; P=0.003\right)$, higher perceived prostate cancer risk $(z=-2.76 ; P=0.006)$, and higher monitoring minus blunting scores $(t=2.10 ; P=0.034)$. A trend was also observed for men who were "definitely interested" in genetic testing to have higher prostate cancer anxiety $(z=-2.58 ; P=0.051)$ and a higher number of first- and second-degree relatives with prostate cancer $(z=-1.71, P=0.088)$. Table 3 shows the logistic regression model for interest in genetic testing. Prostate cancer anxiety was found to be significantly associated with interest in genetic testing (OR 1.03, 95\% CI, 1.00-1.06, $P=0.030$ ). An interaction was also found between number of first- and second-degree relatives and recruitment source; an increasing number of first- and second-degree relatives was found to be associated with interest in genetic testing among the family study sample (OR 1.73, 95\% CI, 1.17-2.55, $P=0.006$ ), but not the self-selected sample (OR 0.81, 95\% CI, $0.46-1.45, P=0.48$ ).

Two hundred twenty four respondents gave reasons why they believed genetic testing would or would not be helpful. These are listed in Table 4. Genetic testing was commonly perceived as helpful because it would enable the respondent to make changes, provide psychological benefit and/or facilitate early detection, treatment and cure. Lack of perceived relevance and psychological concerns were reasons for lack of interest in genetic testing.

\section{Potential risk-modifying behavior changes in response to test results}

A majority (93\%) of men reported that a positive genetic test would motivate them to make at least one change to their behavior. Men were most likely to change the frequency or type of check-ups, with $86 \%$ and $83 \%$ identifying these options respectively. Excluding surveillance practices, $84 \%$ of men said they would make at least one health behavior change. Men were least likely to intend to change smoking practices, with only $49 \%$ identifying this item. The greatest change in behavior was for diet and medication/natural therapy with $81 \%$ and $70 \%$, respectively, reporting willingness to change. For all items except smoking, more men indicated they would change their behavior in response to a positive genetic test than believed in the potentially risk-modifying role of that item.

\section{DISCUSSION}

Currently, specialist clinical services for men with an increased risk of developing prostate cancer on the basis of their family history are not available in Australia: genetic testing is hypothetical as the genetic basis of prostate cancer risk has not been fully elucidated and preventive measures remain an area of research. However, should such services be established, it is important to have some insight into the beliefs men might hold about their options before attending a service ${ }^{37}$ and actions they may have already undertaken to reduce their risk. We have previously reported that the greatest need of men with a family history of prostate cancer was to obtain information about risk management ${ }^{25}$ and that most are managing their risk by undergoing surveillance. ${ }^{26}$ In this study, we extend these data by considering other modifications men have made to their health behavior, finding that $39 \%$ reported having made changes in response to their family history alone. For instance, the belief that diet could affect risk was widely held $(73 \%)$ and many $(27 \%)$ had already modified their diet on the basis of their family history. The majority of respondents (84\%) stated they would make further changes to health behaviors (other than surveillance) in response to genetic test results and the perception that genetic testing would help the respondent to make changes, including lifestyle changes, and result in improved health outcomes was common. As respondents were told only that genetic testing was not available and were not given any further information or speculation about the nature of genetic testing in the future, this data represents the "naïve" view of at-risk men before any intervention, such as genetic counseling. Nonetheless, the reasons given by respondents for why genetic testing would be helpful are broadly consistent with reasons cited by men in the general population after watching an educational video on prostate cancer genetic testing. ${ }^{38}$ To our knowledge, these are the first reported data on men's health attitudes and health behaviors in response to their increased familial risk of prostate cancer and their intentions to change behaviors in response to genetic testing.

The high level of interest in genetic testing by men with some family history of prostate cancer found here is consistent with other reports, ${ }^{31,39,40}$ as is the association with the number of affected first- and second-degree relatives (and thus a higher objective risk). ${ }^{39,41}$ We also found that interest was predicted by prostate cancer anxiety but did not find associations previously reported in studies with men with some family history of prostate cancer, namely: having sons or children, ${ }^{31,42}$ lower 
Table 2

Factors associated with interest in genetic testing for prostate cancer

\begin{tabular}{|c|c|c|c|c|c|}
\hline $\begin{array}{l}\text { Variable "definitely" } \\
\text { Independent variable }\end{array}$ & Level "definitely" & $N$ & Percentage definitely interested & $\chi^{2}$ & $P$ \\
\hline \multirow[t]{2}{*}{ Educational level } & No postschool education & 143 & 69 & 0.02 & 0.89 \\
\hline & Postschool education & 124 & 69 & & \\
\hline \multirow[t]{2}{*}{ Recruitment source } & Family study & 151 & 61 & 8.98 & 0.003 \\
\hline & Self-selected & 122 & 78 & & \\
\hline \multirow[t]{2}{*}{ Sons } & Sons & 76 & 68 & 0.00 & 0.99 \\
\hline & No sons & 196 & 68 & & \\
\hline \multirow[t]{2}{*}{ Marital status } & Partnered & 228 & 70 & 0.98 & 0.32 \\
\hline & Not partnered & 45 & 62 & & \\
\hline Dependent variable & & & Mean (SD) & $t$ - or $z$-value & \\
\hline \multirow[t]{2}{*}{ Age } & Definitely interested & 186 & $57(9.8)$ & 1.39 & 0.17 \\
\hline & Other & 92 & $59(10.7)$ & & \\
\hline \multirow{2}{*}{$\begin{array}{l}\text { Perceived prostate cancer } \\
\text { risk }\end{array}$} & Definitely interested & 185 & $57(25.8)$ & -2.76 & 0.006 \\
\hline & Other & 84 & $47(26.8)$ & & \\
\hline \multirow[t]{2}{*}{ No. FDRs and SDRs ${ }^{a}$} & Definitely interested & 187 & 1.55 & -1.71 & 0.088 \\
\hline & Other & 86 & 1.30 & & \\
\hline \multirow[t]{2}{*}{ Prostate cancer anxiety } & Definitely interested & 171 & $9(12.0)$ & -1.95 & 0.051 \\
\hline & Other & 86 & $6(9.4)$ & & \\
\hline \multirow{2}{*}{$\begin{array}{l}\text { Monitoring minus blunting } \\
\text { score }\end{array}$} & Definitely interested & 184 & $6(3.9)$ & -2.1 & 0.034 \\
\hline & Other & 85 & $5(3.6)$ & & \\
\hline
\end{tabular}

${ }^{a}$ Refers to number of first- and second-degree relatives with prostate cancer.

Table 3

Logistic regression of predictors of interest in genetic testing for prostate cancer $(N=248)$

\begin{tabular}{|c|c|c|c|c|c|}
\hline Variable & Reference group & $-2 \log$ likelihood ( $P$ value $)$ & OR & $95 \%$ CI & $P$ \\
\hline Recruitment source & Family study ${ }^{a}$ & $290.47(P<0.001)$ & 6.44 & $2.17-19.18$ & 0.001 \\
\hline FDRs and SDRs ${ }^{b}$ & & & 3.69 & $1.41-9.69$ & 0.008 \\
\hline Recruitment source $\times$ FDRs and SDRs & & & 0.47 & $0.24-0.94$ & 0.033 \\
\hline Prostate cancer anxiety & & & 1.03 & $1.00-1.06$ & 0.030 \\
\hline
\end{tabular}

${ }^{a}$ Refers to reference category.

${ }^{b}$ Refers to number of first- and second-degree relatives with prostate cancer.

educational level, ${ }^{42,43}$ and being married. ${ }^{44}$ These discrepancies may reflect the different populations and family histories of those sampled.

\section{A theoretical perspective}

Leventhal's common sense model (CSM) of the self-regulation of illness has been suggested as a basis for studies on genetic susceptibility and response to genetic testing ${ }^{45-47}$ and as a useful framework for conceptualizing genetic counseling. ${ }^{18} \mathrm{Al}-$ though our study is descriptive in nature, and did not use CSM as a theoretical framework, it is intended to inform genetic counseling practice. Consequently, we decided to view our results through the lens of CSM.
CSM is a dual processing model, proposing that people respond to health threats both cognitively and emotionally. The cognitive process proposed in the CSM suggests that the individual constructs a representation of the threat, which includes beliefs about the nature of the threat, its cause, controllability, consequences and perceived duration. These cognitive representations, or beliefs, then guide attempts to control the perceived threat, which may include specific health-related behaviors. In this study, we assessed respondents' beliefs about the effects of health behaviors on risk, which taps into representations of cause and control. Many men believed that one or more behaviors relating to diet, alcohol intake, exercise, medication/natural therapies and vitamin/mineral supplements 
Table 4

Reasons provided for why genetic testing would or would not be helpful

\begin{tabular}{|c|c|c|c|}
\hline Category & Themes & No. responses ${ }^{a}$ & Example (respondent ID) \\
\hline \multicolumn{4}{|c|}{ Reasons why genetic testing would be helpful } \\
\hline \multirow[t]{5}{*}{ Make changes } & Preventive action/intervention & 31 & $\begin{array}{l}\text { It would allow me to take appropriate action to prevent me } \\
\text { getting it }(78)\end{array}$ \\
\hline & Regular checkups & 27 & $\begin{array}{l}\text { If one was more likely to develop PC then would make sure of } \\
\text { regular tests to identify cancer at earliest stage possible (608) }\end{array}$ \\
\hline & To reduce risk (unspecified) & 11 & $\begin{array}{l}\text { I could employ all necessary steps or processes to help reduce the } \\
\text { risk (318) }\end{array}$ \\
\hline & Lifestyle & 10 & $\begin{array}{l}\text { I could take some positive action and prepare for life-style } \\
\text { changes where necessary (303) }\end{array}$ \\
\hline & Nonspecific & 5 & If one is aware of a problem one can do something about it (558) \\
\hline \multirow[t]{4}{*}{ Psychological benefit } & Knowledge, awareness and planning & 28 & It is better to know to assist understanding (171) \\
\hline & Peace of mind & 14 & Puts your mind at ease (9) \\
\hline & Relief from uncertainty & 8 & Not knowing is a pain (647) \\
\hline & Early warning and alertness & 14 & It makes one awake and gives you early warning (269) \\
\hline \multirow[t]{2}{*}{ Early diagnosis } & Nonspecific & 13 & So you could be diagnosed as early as possible (219) \\
\hline & Helps cure and/or improves outcome & 17 & Early diagnosis helps recovery (522) \\
\hline Early treatment & & 29 & Early treatment combats any onset of the disease (645) \\
\hline Cure & & 10 & $\begin{array}{l}\text { Allow for the orderly planning and detection of its onset thus } \\
\text { increasing your chances of being cured or even better } \\
\text { complete protection (646) }\end{array}$ \\
\hline Family history & & 12 & To confirm family link (281) \\
\hline Helpful—unspecified & & 8 & Would be helpful (666) \\
\hline Current testing insufficient & & 7 & Presumably it would be an improvement on the PSA test (543) \\
\hline Community benefit & & 5 & $\begin{array}{l}\text { It would help identify the true magnitude of the condition in the } \\
\text { community (583) }\end{array}$ \\
\hline \multicolumn{4}{|c|}{ Reasons why genetic testing would not be helpful } \\
\hline \multirow[t]{3}{*}{ Lack of personal relevance } & Age & 2 & Too old (7) \\
\hline & No change/uninformative & 8 & $\begin{array}{l}\text { No need to have genetic testing unless it is going to result in } \\
\text { some action to prevent PC (294) }\end{array}$ \\
\hline & Other risk factors & 1 & I think it has more to do with the poor western way of life (145) \\
\hline Psychological concerns & & 4 & It would cause more stress if positive (25) \\
\hline
\end{tabular}

${ }^{a}$ Responses may be included in more than one theme.

PC, prostate cancer.

would modify their risk, and a large proportion had undertaken such changes in response to their family history. However, objective and perceived risk were not related to behavior change: this is consistent with the CSM which proposes that it is the beliefs about the threat that influence behavior (e.g., beliefs about controllability) rather than the magnitude of the risk per se.

As well as this cognitive process, the CSM describes a parallel process of emotional reaction to the health threat, which triggers coping strategies to reduce distress. Genetic testing can be conceived as a coping strategy, ${ }^{46}$ which may serve to reduce worry and concern and increase feelings of control. Men experiencing anxiety about their risk of prostate cancer were significantly more likely to be definitely interested in genetic testing than those who were not in the study and an association between worry and distress and intention to test has been observed in another study of prostate cancer risk, ${ }^{39}$ as well as studies in a range of other genetic conditions. ${ }^{46}$ Expectations that undergoing genetic testing will provide an unaffected individual relief from anxiety are realistic for noncarriers, although carriers do not seem to have adverse outcomes in the medium-long term. ${ }^{48}$ The possibility that genetic testing may offer a sense of control and reduce threat is supported by respondents' beliefs that it would facilitate early diagnosis, treatment and cure, as well as being a catalyst for behavioral changes that may reduce risk and provide psychological benefit. However, the actual impact of genetic testing on behavior and cognitive representations remains to be seen. A randomized 
control trial of the psychological impact of genetic testing for familial hypercholesterolemia found that people with mutations believed less strongly than noncarriers in the efficacy of diet in reducing cholesterol levels and showed a trend for carriers to believe more strongly in the efficacy of cholesterol lowering medication. ${ }^{49}$ Interestingly, our study indicates that the largest change from actual practice to intended behavior in response to genetic testing was the intention to take medication.

\section{Study limitations}

As indicated earlier, this study was not designed explicitly to test the CSM model and further work is required to explore cognitive and emotional representations in this group. A number of further caveats must be made when considering the implications of our results. First, because of our focus on service development, we adopted a recruitment strategy that deliberately targeted those likely to attend genetic counseling services for cancer-either because they have a significant risk of the condition or because they are concerned about their family history-rather than a representative sample of all men with a family history of prostate cancer. ${ }^{25}$ The results in this study therefore cannot be generalized to all men with a family history of this cancer. The ability to generalize findings is also limited by the response of $59 \%$, although this compares favorably with responses of $42-50 \%$ reported in other recent studies of unaffected Australian men and prostate cancer ${ }^{50}$ and familial cancer. ${ }^{51}$ Second, results relating to the magnitude of interest in genetic testing and intention to change behavior should be viewed as a "best case scenario." Actual test uptake by people with other types of familial cancer history is usually lower than the initial intention to be tested. ${ }^{52}$ We attempted to adjust for this by comparing those who would definitely undergo testing with all others (including those who would "probably" undergo testing) as it seemed reasonable to assume that those with a relatively weaker intention to test would be those most likely not to pursue it. However, the precise magnitude of interest must be treated with some caution. In a similar vein, willingness to undertake preventive action should not be overinterpreted as reflecting the likely magnitude of response: there is often a gap between intention to change and actual alterations in behavior. Finally, behaviors are self-reported and we cannot know how accurately or to what extent men have altered their conduct. In the case of diet, men may not always be aware that a change has been made. For instance, the partner of one respondent stated that she had altered their diet because of his family history of prostate cancer, although the respondent himself was unaware of this change.

\section{Clinical implications}

Our intention in conducting this study was to inform the development of clinical services and genetic counseling that "[presents] information in a way that allows individuals to appreciate the threat reduction they might achieve by engaging in the recommended action and facilitating their ability to perform the behavior." ${ }^{47}$ Shiloh ${ }^{18}$ recommends that those provid- ing genetic counseling should inter alia explore specific representations that clients have about the condition before predicting or trying to modify their knowledge and reactions. Although it is premature to make definitive statements about how genetic counseling should be provided for this condition, the results presented here support Leventhal's CSM of the selfregulation of health and illness. The perceived benefits of hypothetical genetic testing for prostate cancer genetic testing are consistent with findings from related studies on individuals undergoing genetic testing for hereditary nonpolyposis colorectal cancer and hereditary breast ovarian cancer, ${ }^{53}$ which underscore individuals' desire to prevent cancer and have appropriate medical management. However, if agents such as antiandrogens and selenium are found to have clinical use in the prevention of prostate cancer in men with a family history, then a genetic condition which can be treated by medication, such as familial hypercholesterolemia, may be a more relevant clinical model to draw on than the hereditary cancer susceptibility syndromes, where the focus is currently on surveillance and surgical management.

In Australia there has not to date been a focus on familial prostate cancer: specialist services analogous to those for hereditary nonpolyposis colorectal cancer and hereditary breast ovarian cancer are not available and prostate cancer family history as a risk factor has not attracted noticeable media coverage or health promotion campaigns. In the absence of these programs, our data provide an insight into the pre-existing beliefs of men at increased risk of prostate cancer and may inform the development of future targeted health campaigns and prostate cancer services.

\section{CONCLUSIONS}

There is insufficient evidence for lifestyle and health behavior changes as a means of reducing prostate cancer risk to warrant either clinical intervention or public health campaigns. However, this may change as the results of current research on preventive agents and on the genetic basis of prostate cancer susceptibility become available. The data presented indicate that men with a family history of prostate cancer believe that their risk of this condition is influenced by lifestyle choices and demonstrate a willingness to engage in preventive practices. Evidence suggests that interventions based on theories of behavior change are more effective than the simple provision of information alone. ${ }^{54,55}$ Our study supports further investigation of the CSM as a basis for the delivery of genetic counseling services and the development of interventions to educate and modify the health behavior of men at increased risk of prostate cancer due to their family history.

\section{ACKNOWLEDGMENTS}

Bettina Meiser and Geoffrey Lindeman were supported by a Career Development Award and Senior Research Fellowship from The National Health and Medical Research Council of Australia, respectively. 


\section{Cowan et al.}

We are most grateful for the valuable contribution of all the men and their partners who participated in this study. We thank Dr. Gwyneth Rees for invaluable advice on the Common Sense Model, Professor Anthony Costello for methodological advice and facilitation of access to the study samples. Helen Crowe and Charmaine Smith assisted with recruitment and Robert MacInnis advised on statistical analysis during the early stages of this project.

\section{References}

1. Lantz JM, Fullerton JT, Harshburger RJ, Sadler GR. Promoting screening and early detection of cancer in men. Nurs Health Sci 2001;3:189-196.

2. Smith JA, Braunack-Mayer A, Wittert G. What do we know about men's helpseeking and health service use? Med J Aust 2006;184:81-83.

3. Marteau TM, Croyle RT. The new genetics. Psychological responses to genetic testing. BMJ 1998;316:693-696.

4. Meiser B, Collins V, Warren R, Gaff C, et al. Psychological impact of genetic testing for hereditary non-polyposis colorectal cancer. Clin Genet 2004;66:502-511.

5. Department of Health (UK). Our inheritance, our future: realising the potential of genetics in the NHS. Stationary Office, 2003.

6. Collins VR, Meiser B, Ukoumunne OC, Gaff C, et al. The impact of predictive genetic testing for hereditary nonpolyposis colorectal cancer: three years after testing. Genet Med 2007;9:290-297.

7. Bermejo-Perez MJ, Marquez-Calderon S, Llanos-Mendez A. Effectiveness of preventive interventions in BRCA1/2 gene mutation carriers: a systematic review. Int $J$ Cancer 2007;121:225-231.

8. Lindor NM, Petersen GM, Hadley DW, Kinney AY, et al. Recommendations for the care of individuals with an inherited predisposition to Lynch syndrome: a systematic review. JAMA 2006;296:1507-1517.

9. Bratt O. Hereditary prostate cancer. BJU Int 2000;85:588-598.

10. Albertsen PC. Is screening for prostate cancer with prostate specific antigen an appropriate public health measure? Acta Oncol 2005;44:255-264.

11. Clark LC, Combs GF Jr, Turnbull BW, Slate EH, et al. Effects of selenium supplementation for cancer prevention in patients with carcinoma of the skin. A randomized controlled trial. Nutritional Prevention of Cancer Study Group. JAMA 1996; 276:1957-1963.

12. Lippman SM, Goodman PJ, Klein EA, Parnes HL, et al. Designing the Selenium and Vitamin E Cancer Prevention Trial (SELECT). J Natl Cancer Inst 2005;97: 94-102.

13. Thompson IM, Goodman PJ, Tangen CM, Lucia MS, et al. The influence of finasteride on the development of prostate cancer. N Engl J Med 2003;349:215-224.

14. Scardino PT. The prevention of prostate cancer-the dilemma continues. N Engl J Med 2003;349:297-299.

15. Moyad MA, Carroll PR. Lifestyle recommendations to prevent prostate cancer, part II: time to redirect our attention? Urol Clin North Am 2004;31:301-311.

16. Moyad MA, Carroll PR. Lifestyle recommendations to prevent prostate cancer, part I: time to redirect our attention? Urol Clin North Am 2004;31:289-300.

17. Biesecker BB, Marteau TM. The future of genetic counselling: an international perspective. Nat Genet 1999;22:133-137.

18. Shiloh S. Illness representations, self-regulation, and genetic counseling: a theoretical review. J Genet Couns 2006;15:325-337.

19. Michie S, Smith JA, Senior V, Marteau TM. Understanding why negative genetic test results sometimes fail to reassure. Am J Med Genet 2003;119A:340-347.

20. Michie S, Weinman J, Miller J, Collins V, et al. Predictive genetic testing: high risk expectations in the face of low risk information. J Behav Med 2002;25:33-50.

21. Shiloh S, Ben-sinai R, Keinan G. Effects of controllability, predictability and information-seeking style on interest in predictive genetic testing. Pers Soc Pychol Bull 1999;25:1187-1195.

22. Miller SM. Monitoring and blunting: validation of a questionnaire to assess styles of information seeking under threat. J Pers Soc Psychol 1987;52:345-353.

23. Staples MP, Giles GG, English DR, McCredie MR, et al. Risk of prostate cancer associated with a family history in an era of rapid increase in prostate cancer diagnosis (Australia). Cancer Causes Control 2003;14:161-166.

24. Gaff CL, Aragona C, MacInnis RJ, Cowan R, et al. Accuracy and completeness in reporting family history of prostate cancer by unaffected men. Urology 2004;63: 1111-1116.

25. Gaff CL, Cowan R, Meiser B, Lindeman G. Genetic services for men: the preferences of men with a family history of prostate cancer. Genet Med 2006;8:771-778.

26. Meiser B, Cowan R, Costello A, Giles GG, et al. Prostate cancer screening in men with a family history of prostate cancer: the role of partners in influencing men's screening uptake. Urology 2007;70:738-742.
27. Streiner DL, Norman GR. Health measurement scales. Oxford: Oxford University Press, 1995.

28. Valdimarsdottir H, Bovbjerg D, Kash K, Holland J, et al. Psychological distress in women with a familial risk of breast cancer. Psychooncology 1995;4:133-141.

29. Zakowski SG, Valdimarsdottir HB, Bovbjerg DH, Borgen P, et al. Predictors of intrusive thoughts and avoidance in women with family histories of breast cancer. Ann Behav Med 1997;19:362-369.

30. Horowitz M, Wilner N, Alvarez W. Impact of event scale: a measure of subjective stress. Psychosom Med 1979;41:209-218.

31. Bratt O, Damber JE, Emanuelsson M, Kristoffersson U, et al. Risk perception, screening practice and interest in genetic testing among unaffected men in families with hereditary prostate cancer. Eur J Cancer 2000;36:235-241.

32. Meiser B, Butow P, Barratt A, Friedlander M, et al. Breast cancer screening uptake in women at increased risk of developing hereditary breast cancer. Breast Cancer Res Treat 2000;59:101-111.

33. Zigmond A, Snaith R. The hospital anxiety and depression scale. Acta Psychiatr Scand 1983;67:361-370

34. Ibbotson T, Maguire P, Selby P, Priestman T, et al. Screening for anxiety and depression in cancer patients: the effects of disease and treatment. Eur J Cancer 1994, 30A:37-40.

35. Moorey S, Greer S, Watson M, Gorman C, et al. The factor structure and factor stability of the hospital anxiety and depression scale in patients with cancer. $\mathrm{Br} \mathrm{J}$ Psychiatry 1991;158:255-259.

36. Ropka ME, Wenzel J, Phillips EK, Siadaty M, et al. Uptake rates for breast cance genetic testing: a systematic review. Cancer Epidemiol Biomarkers Prev 2006;15:840 855.

37. Cooper AF. Whose illness is it anyway? Why patient perceptions matter. Int J Clin Pract 1998;52:551-556.

38. Doukas DJ, Fetters MD, Coyne JC, McCullough LB. How men view genetic testing for prostate cancer risk: findings from focus groups. Clin Genet 2000;58:169-176.

39. Diefenbach MA, Schnoll RA, Miller SM, Brower L. Genetic testing for prostate cancer. Willingness and predictors of interest. Cancer Pract 2000;8:82-86.

40. Myers RE, Hyslop T, Jennings-Dozier K, Wolf TA, et al. Intention to be tested for prostate cancer risk among African-American men. Cancer Epidemiol Biomarker Prev 2000;9:1323-1328.

41. Cormier L, Valeri A, Azzouzi R, Fournier G, et al. Worry and attitude of men in at-risk families for prostate cancer about genetic susceptibility and genetic testing. Prostate 2002;51:276-285.

42. Bratt O, Kristoffersson U, Lundgren R, Olsson H. Sons of men with prostate cancer: their attitudes regarding possible inheritance of prostate cancer, screening, and genetic testing. Urology 1997;50:360-365.

43. Doukas DJ, Li Y. Men's values-based factors on prostate cancer risk genetic testing: a telephone survey. BMC Med Genet 2004;5:28.

44. Weinrich S, Royal C, Pettaway CA, Dunston G, et al. Interest in genetic prostate cancer susceptibility testing among African American men. Cancer Nurs 2002;25: $28-34$.

45. Rees G, Fry A, Cull A, Sutton S. Illness perceptions and distress in women at increased risk of breast cancer Psych Health 2004;19:749-765.

46. Gooding HC, Organista K, Burack J, Biesecker BB. Genetic susceptibility testing from a stress and coping perspective. Soc Sci Med 2006;62:1880-1890.

47. Marteau TM, Weinman J. Self-regulation and the behavioural response to DNA risk information: a theoretical analysis and framework for future research. Soc Sci Med 2006;62:1360-1368.

48. Meiser B. Psychological impact of genetic testing for cancer susceptibility: an update of the literature. Psychooncology 2005;14:1060-1074.

49. Marteau T, Senior V, Humphries SE, Bobrow M, et al. Psychological impact of genetic testing for familial hypercholesterolemia within a previously aware population: a randomized controlled trial. Am J Med Genet A 2004;128:285-293.

50. Giles GG, Severi G, English DR, McCredie MR, et al. Sexual factors and prostate cancer. BJU Int 2003;92:211-216.

51. Lobb E, Hallowell N, Pepall E, Kristjanson L, et al. What do men want?: the expectations of the familial clinic of men from high risk breast cancer families. Psychooncology 2006;15:S1-S478.

52. Lerman C, Croyle RT, Tercyak KP, Hamann H. Genetic testing: psychological aspects and implications. J Consult Clin Psychol 2002;70:784-797.

53. Balmana J, Stoffel EM, Emmons KM, Garber JE, et al. Comparison of motivations and concerns for genetic testing in hereditary colorectal and breast cancer syndromes. J Med Genet 2004;41:e44.

54. Elder JP, Ayala GX, Harris S. Theories and intervention approaches to health-behavior change in primary care. Am J Prev Med 1999;17:275-284.

55. Jepson R. The effectiveness of interventions to change health-related behaviours: a review of reviews. Glasgow: Medical Research Council, MRC Social \& Public Health Sciences Unit, University of Glasgow, 2000. 